Canadian Journal of Higher Education

Revue canadienne d'enseignement supérieur

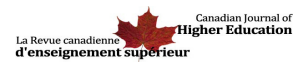

\title{
Policy Analysis of Equity, Diversity and Inclusion Strategies in Canadian Universities - How Far Have We Come?
}

\section{Merli Tamtik and Melissa Guenter}

Volume 49, Number 3, 2019

URI: https://id.erudit.org/iderudit/1066634ar

DOI: https://doi.org/10.7202/1066634ar

\section{See table of contents}

Publisher(s)

Canadian Society for the Study of Higher Education

ISSN

2293-6602 (digital)

Explore this journal

Cite this article

Tamtik, M. \& Guenter, M. (2019). Policy Analysis of Equity, Diversity and Inclusion Strategies in Canadian Universities - How Far Have We Come? Canadian Journal of Higher Education / Revue canadienne d'enseignement supérieur, 49(3), 41-56. https://doi.org/10.7202/1066634ar

\section{Article abstract}

Institutional efforts to address equity, diversity and inclusion in educational settings have been often met with overwhelmingly critical accounts pointing towards well-intentioned attempts that have reinforced exclusion and inequity. A new wave of recent developments among Canadian research-intensive universities (U15) is providing a slightly different account of universities' involvement in addressing the needs of equity-seeking students. This paper presents data collected through policy analysis of 50 strategic documents from 15 Canadian universities from 2011-2018. The findings suggest that equity, diversity and inclusion activities have become a policy priority attached to a variety of institutional action plans and performance reports. As a result, there has been an increase in institutional strategic activities including institutional political commitment (e.g. new equity offices, new senior administration positions, mandatory training), student and faculty recruitment with programmatic and research supports (e.g. diversity admission policies, scholarships, access programs, curriculum changes), accompanied by broader efforts to create supportive institutional climates (e.g. student advisors, awards, celebrations). Inconsistencies emerged amongst how equity is defined in policy documents, resulting in either redistributive or inclusive practices in equity, diversity, and inclusion initiatives.
This document is protected by copyright law. Use of the services of Érudit (including reproduction) is subject to its terms and conditions, which can be viewed online.

https://apropos.erudit.org/en/users/policy-on-use/ 


\title{
POLICY ANALYSIS OF EQUITY, DIVERSITY AND INCLUSION STRATEGIES IN CANADIAN UNIVERSITIES - HOW FAR HAVE WE COME?
}

\author{
\begin{tabular}{c|c} 
MERLI TAMTIK & MELISSA GUENTER \\
UNIVERSITY OF MANITOBA & UNIVERSITY OF MANITOBA
\end{tabular}
}

\begin{abstract}
Institutional efforts to address equity, diversity and inclusion in educational settings have been often met with overwhelmingly critical accounts pointing towards well-intentioned attempts that have reinforced exclusion and inequity. A new wave of recent developments among Canadian research-intensive universities (U15) is providing a slightly different account of universities' involvement in addressing the needs of equity-seeking students. This paper presents data collected through policy analysis of 50 strategic documents from 15 Canadian universities from 2011-2018. The findings suggest that equity, diversity and inclusion activities have become a policy priority attached to a variety of institutional action plans and performance reports. As a result, there has been an increase in institutional strategic activities including institutional political commitment (e.g. new equity offices, new senior administration positions, mandatory training), student and faculty recruitment with programmatic and research supports (e.g. diversity admission policies, scholarships, access programs, curriculum changes), accompanied by broader efforts to create supportive institutional climates (e.g. student advisors, awards, celebrations). Inconsistencies emerged amongst how equity is defined in policy documents, resulting in either redistributive or inclusive practices in equity, diversity, and inclusion initiatives.
\end{abstract}

Keywords: equity, diversity, inclusion, U15, higher education, policy analysis

\section{Résumé}

Les efforts institutionnels visant à prendre en compte l'équité, la diversité et l'inclusion dans les milieux éducatifs ont souvent suscité des réactions extrêmement critiques suggérant que ces tentatives bien intentionnées n'auraient fait que renforcer l'exclusion et les inégalités. Une nouvelle vague de développements au sein du regroupement des universités de recherche du Canada (U15) montre une situation légèrement différente concernant les actions de ces universités pour répondre aux besoins des étudiants à la recherche d'équité. Cet article présente les données recueillies par l'analyse des politiques dans 50 documents stratégiques de 15 universités canadiennes entre 2011 et 2018. Les résultats suggèrent que les activités en matière d'équité, de diversité et d'inclusion sont devenues une priorité associée à divers plans d'action institutionnels et rapports de performance. Par conséquent, les activités stratégiques institutionnelles ont augmenté, y compris l'engagement politique institutionnel (par exemple, nouveaux bureaux d'équité, nouveaux postes de direction, formation obligatoire) et le recrutement d'étudiants et de professeurs avec le soutien de programmes et de recherches (par exemple, politiques d'admission encourageant la diversité, bourses d'études, programmes d'accès, changements curriculaires), accompagnés d'efforts plus larges visant à créer un climat institutionnel favorable (par exemple, conseillers aux étudiants, récompenses, célébrations). Des incohérences sont apparues dans la définition de l'équité entre les documents de politiques, où les pratiques en matière d'équité, de diversité et d'inclusion sont soit redistributives, soit inclusives.

Mots-clés : équité, diversité, inclusion, U15, enseignement supérieur, analyse des politiques

\section{Introduction}

Widespread scholarly attention has been paid to education systems contributing to exclusion and marginalization of students on the basis of ethnicity, ability/disability, gender, sexuality, and religion (Michalski, Cunningham, \& Henry, 2017; Riley, Mentis, \& Kearney, 2016). While Canada enjoys a global image of being politically multicultural and embracing diversity, the persistence of sys- 
temic barriers and implicit biases faced by members of equity-seeking groups in higher education (e.g. women, racialized minorities, Indigenous peoples, and persons with disabilities) remains a critical issue (Clark et al., 2014; Henry et al., 2016). Some scholars have suggested that modern neoliberal universities' efforts towards equity, diversity, and inclusion agendas often amount to no more than institutional rhetoric, "cosmetic diversity", well-worded mission statements, and superficial changes (Harper \& Hurtado, 2007; Henry et al., 2016; Hoffman \& Mitchell, 2016).

Addressing those long-standing systemic barriers associated with higher learning is essential for several reasons. First, meaningful educational experiences are an individual right that helps to secure students' academic, social, and personal success in life (Preston, 2008). As noted by the OECD (2013), well-educated people have better health and higher incomes, engage more in civic activities, and are generally happier. Second, the changing global environments require universities to meet the needs of their increasingly diversified student population. In the Canadian post-secondary context, changing demographics (Gertler, 2016), increased recruitment and retention of international students and faculty (Government of Canada, 2014), multiculturalism as a state ideology (al Shaibah, 2014; St. Denis, 2011), and the growing momentum around the rights of Indigenous peoples (Henry et al., 2016; Pidgeon, 2016; Truth and Reconciliation Commission, 2015) are some leading factors behind the strengthened institutional focus on diversity and equity.

Recently, there has been significant political impetus at both the global and national levels assigned to the inclusivity agenda. For example, the UNESCO 2030 Framework for Education underlines goals for "inclusive and equitable quality education" (UNESCO, 2015, p.3). In Canada, Universities Canada, an organization representing Canadian post-secondary institutions, has developed seven Inclusive Excellence Principles, followed by an Action Plan to advance equity, diversity, and inclusion on campus and in society (Universities Canada, 2017). The latter primarily encourages institutional transparency in terms of providing public access of diversity-related data. Even stronger pressure (with financial consequences) to hold post-secondary institutions accountable for their equity, diversity and inclusion efforts has come from the Canadian federal government. The Minister of Science and Sport launched the Equity, Diversity, and
Inclusion Action Plan in May 2017 (Government of Canada, 2017). In order to receive research funding through the Canada Research Chairs (CRC) ${ }^{1}$ program, all institutions with five or more CRC positions are now required to develop and publish institutional equity, diversity and inclusion (EDI) action plans (Government of Canada, 2018). This high-level political attention, aligned with research funding, has triggered Canadian research-intensive universities to articulate their goals and demonstrate achievements through institutional EDI action plans.

Despite interest in and commitment to equity, diversity and inclusion, there continues to be considerable variations in whether and how institutions of higher learning define, understand, and respond to equity-related issues (al Shaibah, 2014). As many studies have shown, the task of supporting authentic equity and inclusion among students and faculty is multilayered and complex. For some institutions, this means increasing recruitment across diverse student, staff, and faculty groups. For others, it means focusing their efforts on providing institutional supports through targeted programs, support services, and funding (see Pidgeon, Archibald, \& Hawkey, 2014). Some scholars have argued that Canadian institutions of higher learning need to move beyond passively articulating value for diversity in a rote manner to demonstrating active commitments to inclusivity and equity (al Shaibah, 2014; Pidgeon, 2016).

This paper seeks to identify and analyze the emerging organizational strategies and approaches in Canadian research-intensive universities (U15) to foster equity, diversity and inclusion on campus, and consider their broader implications. The following research questions guide the analysis: How are equity, diversity and inclusion defined in institutional policy documents? What are the institutional strategies for achieving diversity, equity, and inclusion on campus, as articulated in institutional strategic documents?

\section{Literature Review}

Equity, diversity and inclusion are complex and often contested terms, in both meaning and enactment. A definition of diversity typically includes race, gender, age, sexual orientation, socio-economic class, and disability, with additional considerations of religion, education, and family/marital status. However, as Chan (2005) notes, diversity is more than a set of categories. It extends to the principles of inclusion, the recognition and valuing of 
difference, and the ability to participate equitably in society. Equity is most often associated with the concept of fairness. Many scholars see equity as a mechanism for recognizing systemic power and privilege in higher education (Brennan \& Naidoo, 2008). Savage et al. (2013) pointed out that different understandings of equity lead to different education policy foci: for example, an understanding of equity as fairness would suggest policies that focus on redistribution while one of equity as inclusion and recognition would suggest policies that seek to ameliorate the negative influences of social and cultural difference (p. 162). UNESCO's (2015) approach to inclusion focuses on education systems that remove the barriers limiting the participation and achievement of all learners, that respect diverse needs, abilities, and characteristics, and that eliminate all forms of discrimination in the learning environment.

Policies for diversity and inclusion in Canada have not originated as educational policies but are grounded in the Canadian legal framework and constitutional values. This constitutes a rights-based approach to inclusion. The federal legislation that guides institutional approaches to equity, diversity, and inclusion includes the Canadian Multiculturalism Act (1988), the Charter of Rights and Freedoms (1982), the Employment Equity Act (1986, revised in 1996), and the Canadian Human Rights Act (1977) (Chan, 2005). Each establishes principles and values to be included in Canadian society. In addition, there is provincial legislation that guides and supports institutional practice.

A core focus in Canadian higher education literature has been on the issues around hiring and employment equity (Henry et al., 2016; Kipang \& Zuberi, 2018; Osborne, 2012;). Scholars have pointed to inequities in the representation of racialized faculty and their limited impact in terms of power, prestige, and influence within the university. Unconscious biases have had a significant impact on the career trajectories of racialized and Indigenous scholars and women in the contemporary academy (Henry et al., 2016). However, there is no shortage of scholarship suggesting that equity concerns are equally relevant for student groups. Indigenous students in Canada are consistently faced with barriers, including racism, interpersonal discrimination and misrepresentation or total elimination of Indigenous culture(s) in the curriculum, leading to frustration with the university system and feelings of cultural isolation on campus (Bailey, 2016; Gaudry \& Lorenz, 2018; Pidgeon, 2014; Preston, 2008).
Students with disabilities similarly struggle to integrate into postsecondary environments due to the academic and social barriers related to their impairments (Jalovcic, 2017; Ostrowski, 2016). Recent studies have indicated that international students similarly face challenges integrating into Canadian university life and culture (Guo \& Chase, 2011). International students in Canada are often perceived to be "ideal immigrants" (Scott et al., 2015), "cash," "competition," and "charity" (Stein \& de Andreotti, 2016) in policy documents and in practice. Several authors have pointed to the general discourse shift in Canadian policies whereby international students have moved from being the receivers of development aid to being Canada's solution to filling a void of highly skilled workers (Stein, 2017; Trilokekar, 2010).

Many scholars have emphasized the crucial role of senior administrative leadership and deliberate and sustained conscious administrative planning in securing equity and diversity in a post-secondary education context (Chun \& Evans, 2018; Pidgeon, Archibald, \& Hawkey, 2014). Chan (2005) noted that a system-wide engagement with the debates on diversity and policy is a necessary step in the process of institutional reform and change. Examination of how power is manifested in practice is an important feature of changing institutions. Otherwise, subjective decision-making may continue with privileged groups making decisions for others. An acknowledgement and examination of the complexities and the micropolitics in the institution are essential (Chan, 2005). Pidgeon (2016) has stated that leadership in the Indigenization movement should come from a variety of individuals and groups within and outside the institution and needs to be culturally responsive. She has pointed to the need for involving Indigenous peoples more actively in governance of the university. Diversity action plans, institution-wide Indigenous strategic plans, and other policy documents have been seen as key mechanisms to advance and influence equity, diversity, and inclusion formally (Hurtado, Alvarez, Guillermo-Wann, Cuellar, \& Arellano, 2012; Iverson, 2007). Used as accountability mechanisms, those plans state institutional achievements and progress. This birds-eye view overview of recent studies provides convincing evidence of the struggles that Canadian post-secondary education face in the context of a equity, diversity, and inclusion agenda. 


\section{Theoretical Framework}

This study is informed by the lens of critical policy studies in education (Ball 1990, 1993; Henry et al., 2013; Ozga 2000 ), whereby the concept of policy itself is problematized by highlighting that policies are not only texts and documents but, most importantly, processes that are informed by values, discussion, activities, social relationships and power. Ozga (2000) points out that policies are "struggled over, not delivered" (p. 2). A critical approach to policy analysis thus emphasizes the importance of examining policies within their historical, social, economic, cultural, and political contexts (Diem \& Young, 2015), recognizing that these contexts produce particular local versions of policy (Ozga, 2005; Taylor, 1997). Ball (1990) notes that "policies embody claims to speak with authority, they legitimate and initiate practices in the world, and they privilege certain visions and interests" (p. 22). It is possible to conceptualise policy as a process of continuous cycle of policy making and re-making in specific sites (e.g. universities) through power struggle (among stakeholder groups involved) (Ball, 1993; Bowe, Ball \& Gold, 1992).

A critical policy approach pays attention not only to the content of the policy, but also to the processes of policy development and implementation to evaluate how policy making processes are arranged, what particular set of educational values have been endorsed, to investigate whose interests the policy serves and to examine how a policy has been implemented, and with what outcomes (Henry et al., 2013). In that regard, Hurtado et al.'s (1998) work is especially useful as they propose a four-aspect analytical framework to assess campus climate, often referred as intangible, focusing on: 1) a campus' historical legacy of inclusions or exclusion of various racial or ethnic groups; 2) its structural diversity (i.e., the numerical and proportional representation of diverse groups on campus); 3 ) its psychological climate (i.e., perceptions, attitudes, and beliefs about diversity); and 4) its behavioral climate (i.e., how different racial and ethnic groups interact on campus). In this paper, while engaging in policy analysis, we recognize that policies are more than texts, closely associated with authority and power, leading to local interpretations of equity, diversity and inclusion. Therefore, it is important to consider the values and definitions and institutional strategic responses to understand the nuances and differences in the framings of the issues aligned with the activities emerging from those framings.

\section{Methodology}

This qualitative study reported on the data gathered through content analysis of policy documents from 15 Canadian research-intensive universities. A total of 92 documents were initially collected, from which 50 documents were selected for the final analysis (see Table 1). The selection criteria involved: 1 ) most recent institutional strategic plans; 2) action plans and performance measures directly developed to enhance equity, diversity, and inclusion on campus (including internationalization strategies); 3) public accessibility (posted on websites). Short institutional diversity and equity statements were not included, as more detailed documents were available. Diversity and equity offices (if available) or other senior administration representatives from each university were contacted for document verification purposes.

Textual analysis through inductive categorization (Burnard, 1991) was performed, gradually developing higher order groups and unique themes within the broader groups (Creswell, 1998; Elo \& Kyngäs, 2008). The first step of the analysis involved free/open coding, where categorical themes were identified through reading and making notes to the texts. For example, any mention made in regard to the word of equity and/or diversity and/ or inclusion, the frequency and the specific contextual association of the terms was highlighted. Based on the results, the lists of categories emerged, which were then grouped under higher order headings (e.g. presence and values associated with the definitions, activities related to hiring, research, training, curriculum, learning, student support, recruitment, campus culture). Next, the data was examined, compared and interpreted, and then classified as 'belonging' to a particular broader group or not. Through abstraction, a general description of the broader research categories was achieved by creating six main categories with distinctive themes within each. Each researcher conducted their own categorization independently. Content validation was achieved through several meetings among the researchers to agree upon the way in which the data was categorized and distinct themes identified.

In the analysis, we looked at how equity, diversity and inclusion had been addressed and framed, and what institutional initiatives had been proposed and adopted (performance reports). In each document, we analyzed the content and paragraphs that specifically addressed the institutional approach, goals, and activities related 
to EDI. Furthermore, we also paid attention to the missing discourses, e.g. whose voices (which social groups) were not reflected in those documents.

\section{Findings}

The findings are presented following the main six categories that emerged from the data analysis -1 ) definitions;

Table 1. List of the policy documents analyzed

\begin{tabular}{|c|c|}
\hline University & Documents \\
\hline University of Alberta (AB) & $\begin{array}{l}\text { 1. Institutional Strategic Plan "For the Public Good" (2016-2021) } \\
\text { 2. "For the Public Good". Annual Performance Measures (November 2018) } \\
\text { 3. Political Policy Internationalization (2013-2020) } \\
\text { 4. CRC Equity, Diversity \& Inclusion Action Plan (2018) }\end{array}$ \\
\hline University of Calgary (AB) & $\begin{array}{l}\text { 1. Strategic Plan “Eyes High" (2017-2022) } \\
\text { 2. Office of Diversity, Equity and Protected Disclosure Annual Report (2016-2017) } \\
\text { 3. University of Calgary International Strategy (2013) } \\
\text { 4. CRC Equity Diversity and Inclusion Action Plan (2018) }\end{array}$ \\
\hline Dalhousie University (NS) & $\begin{array}{l}\text { 1. Strategic Priority Charter \#DalForward (2014-2018) } \\
\text { 2. Diversity and Inclusiveness Strategy Progress Report (2018) } \\
\text { 3. Institutional Equity, Diversity, Inclusion Action Plan CRC (2017) }\end{array}$ \\
\hline Laval University (QC) & $\begin{array}{l}\text { 1. Strategic Plan "Dare, Inspire, Achieve, Building the Future Together" (2017-2022) } \\
\text { 2. Plan d'action en matière d'équité, de diversité et d'inclusion, CRC (2018) (in French) }\end{array}$ \\
\hline University of Manitoba (MB) & $\begin{array}{l}\text { 1. Strategic Plan "Taking Our Place" (2015-2020) } \\
\text { 2. International Strategy “Manitoba's Gateway to the World" (2014) } \\
\text { 3. Diversity and Inclusion Strategy (2014) } \\
\text { 4. Equity, Diversity, and Inclusion Action Plan for the CRC program (2018) }\end{array}$ \\
\hline McGill University (QC) & $\begin{array}{l}\text { 1. Strategic Academic Plan (2017-2022) } \\
\text { 2. Canada Research Chairs EDI Action Plan (2018) }\end{array}$ \\
\hline McMaster University (ON) & $\begin{array}{l}\text { 1. Strategic Plan (2016-2021) } \\
\text { 2. Internationalization Strategy "The McMaster Model for Global Engagement" (2016) } \\
\text { 3. Equity and Inclusion Office Annual Report "Brighter World" (2016-2017) } \\
\text { 4. Canada Research Chairs: Equity, Diversity \& Inclusion (2018) }\end{array}$ \\
\hline Montreal University (QC) & $\begin{array}{l}\text { 1. Strategic Plan "Planification Stratégique" (2016-2021) } \\
\text { 2. Plan d'action en matière d'équité, de diversité et d'inclusion pour le programme des } \\
\text { chaires de recherche du Canada (2018) }\end{array}$ \\
\hline University of Ottawa (ON) & $\begin{array}{l}\text { 1. Strategic Plan "Destination 2020. Discover the future" (...-2020) } \\
\text { 2. Internationalization Strategy (2017) } \\
\text { 3. Report to the President: Diversity and Inclusion - Challenge and Promise (2018) } \\
\text { 4. Canada Research Chairs Institutional Equity, Diversity, Inclusion Action Plan (2017-2019) }\end{array}$ \\
\hline Queen's University (ON) & $\begin{array}{l}\text { 1. Strategic Framework (2014-2019) } \\
\text { 2. Strategic Framework Year Three Implementation Report (2018) } \\
\text { 3. Equity, Diversity and Inclusion: Action Plan for Recruiting, Hiring and Retaining Canada } \\
\text { Research Chairs at Queen's University (2018) } \\
\text { 4. Principal's Implementation Committee on Racism, Diversity, and Inclusion Implementa- } \\
\text { tion Report (2018) }\end{array}$ \\
\hline University of Saskatchewan (SK) & $\begin{array}{l}\text { 1. University Plan 2025. Strategic Framework and Narrative (2018-2025) } \\
\text { 2. CRC Program: Equity, Diversity and Inclusion (2017) }\end{array}$ \\
\hline
\end{tabular}




\begin{tabular}{|c|c|}
\hline University & Documents \\
\hline University of Toronto (ON) & $\begin{array}{l}\text { 1. Strategic Research Plan “Excellence, Innovation, Leadership” (2018-2023) } \\
\text { 2. Three Priorities: A Discussion Paper (2015) } \\
\text { 3. Canada Research Chairs Equity, Diversity and Inclusion Action Plan (2018) }\end{array}$ \\
\hline $\begin{array}{l}\text { University of British Columbia } \\
\text { (UBC) (BC) }\end{array}$ & $\begin{array}{l}\text { 1. Strategic Plan "Shaping UBC's next century" 2018-2028 } \\
\text { 2. Strategy for Advancing Equity and Diversity "Valuing Difference" (2010) } \\
\text { 3. International Strategic Plan (2011) } \\
\text { 4. CRC Equity, Diversity and Inclusion Action Plan (2018) }\end{array}$ \\
\hline University of Waterloo (ON) & $\begin{array}{l}\text { 1. Strategic Plan "A Distinguished Past - A Distinctive Future" (2013) } \\
\text { 2. Strategic Plan for equity "New Directions" (2013) } \\
\text { 3. International Strategic Plan “Part of Your World" (2013) } \\
\text { 4. CRC Equity, Diversity, and Inclusion Action Plan (2017) }\end{array}$ \\
\hline Western University (ON) & $\begin{array}{l}\text { 1. Strategic Plan "Achieve Excellence on the World Stage" (2014) } \\
\text { 2. Diversity and Inclusion Plan (2011-2015) } \\
\text { 3. International Action Plan (2014-2019) } \\
\text { 4. Canada Research Chairs Program - Equity, Diversity \& Inclusion Action Plan (web only) }\end{array}$ \\
\hline
\end{tabular}

2) political commitment; 3) student recruitment; 4) programmatic supports; 5) research and scholarship; and 6) institutional climate. Within each category distinctive themes are examined and explained.

\section{Defining Equity, Diversity, and Inclusion}

This section highlights the key findings regarding the use of terminology and language as well as value statements made to frame the topic of equity, diversity and/or inclusion. Institutional Strategic Plans across all 15 universities were characterized by the use of broad and vague language in regard to equity, diversity and inclusion. Phrases such as "we value diversity, inclusivity and equity" (Alberta); "we celebrate diversity in all its forms" (Laval), and "commitment to integrity, equity, diversity" (Waterloo) were typical examples of the statements made in the strategic plans. There was a tendency across institutional policy documents to treat all equity, diversity and inclusion issues as one, and consequently to compile all objectives and activities together. This suggests a slogan-like approach to diversity, potentially overlooking the detailed complexities within each term. This finding is not surprising, as scholars have documented the use of broad language in institutional policies before (Henry et al., 2016). A unique statement was found in Dalhousie's Diversity and Inclusiveness Progress Report, which stated that "equity, diversity and inclusiveness are related but distinct goals which must be addressed together, not in isolation" (Dalhousie University, 2018, p. 4). This lens al- lows for taking a more informed organizational approach with distinguishing activities yet integrating approaches for a systemic change.

Only five universities out of fifteen included a formal definition in their policy documents on equity, diversity and/or inclusion. Most expressed institutional principles or purposes rather than stating definitions (e.g. "we are committed to proactively identifying barriers to inclusion"). There were two distinct ideological approaches apparent in relation to equity - equity as fairness versus equity as inclusion. Four universities (Dalhousie, McGill, UBC and Waterloo) viewed equity as a concept of fairness, mentioning "acknowledgement of systemic power and privilege" and stating the need for "redistribution of resources". A more common approach among the universities was viewing equity as a concept of inclusion, which requires focusing on identifying and removing social and cultural barriers. Six universities explicitly mentioned "removing structural barriers" and "identifying and addressing informal obstacles, barriers, and biases" that limit equitable access and opportunities for equity-seeking groups. As noted in the literature (Clarke, 2014), equity as inclusion allows for organizations to change, so that all individuals can achieve the basic minimum, while equity as fairness allows for changes that can potentially secure the maximum success for equity-seeking groups. Giving up privilege to support the maximum for equity-seeking groups seems to be the less frequently promoted implementation approach among the Canadian universities.

Institutional Performance Reports provided further 
details on the framing of the topic by stating indicators and mechanisms universities have adopted to tackle diversity objectives. Indicators such as recruitment statistics, composition of student body (out of town, out of province, outside of Canada, self-identified as Indigenous, women, visible minorities, people with disabilities), student graduation and retention numbers, students' satisfaction with learning, and perception of teaching were some markers used in those reports. Driven by the $\mathrm{CRC}$ program requirements, there are four federally designated equity groups that universities use to gather faculty-specific information - women, racialized/visible minorities, persons with disabilities, and Indigenous persons. These categories leave out some equity-seeking groups such as gender and sexual minorities or international scholars. Another weakness of the CRC reports is that they focus primarily on researcher hiring procedures and do not really get to the systemic issues faced by the broader campus community (e.g. students, staff, teaching faculty). We found that equity, diversity and inclusion indicators are largely defined along the lines of federal performance criteria, with only a few institutions aiming to identify institution-specific barriers with the potential of including initiatives that are specifically designed to help issues facing students and other campus community at a particular university.

\section{Strategies Related to Political Commit- ment}

A theme of political commitment emerged to encompass activities dedicated to changes in the organizational structure: hiring decisions at the highest leadership level to include people with diverse lived experiences; funding decisions to support EDI initiatives, and creating space for equity, diversity, and inclusion activities. Informed by our theoretical framework we also examined the stakeholder groups listed in the documents that were involved in developing policy. The data indicated that the institutional strategic plans were mostly created by the university senior leadership with input from student associations, community groups, government representatives and governance committees. Specific statements to include equity-seeking groups for strategic input were mostly not apparent. The involvement of equity-seeking stakeholder groups was more evident in CRC plans where six universities listed participation from the Equity Officers/Consultants, Vice Provost Equity or individuals from Human Resources and Equity offices. In institutional annual EDI reports the participation of equity-seeking stakeholder groups was most frequently mentioned, with eight universities stating involvement of equity-seeking groups. However, general statements such as "Ad Hoc Committee on Equity", "Provost Advisory Committee" or "Anti-Racism Committee" were made without adding details on who were the individuals actually included. Collaborations with student associations (Waterloo's EDI Plan) and faculty unions (Western's CRC Plan) as a stakeholder group were not mentioned often. Overall, it is evident that policy decisions are still largely made by the university leadership, consisting of a privileged racial group. More work can be done to include explicit voices of people from under-represented groups such as women, people from racialized minority groups, LGBTQ groups, Indigenous communities, international students and faculty in involving them in decision-making regarding institutional EDI policy.

Political commitment is most often associated with changes in the organizational structure and hiring decisions within administrative leadership of the universities. Our findings suggested that seven of the 15 universities have created separate equity, diversity and inclusion offices-University of Calgary, McMaster University, UBC, McGill, Waterloo, University of Toronto, and Queen's University. These offices have designated financial and human capacity to collect information, provide training, organize activities, and suggest recommendations to senior leadership regarding inclusion-related issues on campus.

Some universities have opted to create high-level senior leadership positions related to equity, diversity and inclusion. For example, UBC (in 2015) and McMaster University (in 2018) appointed new Associate Vice-Presidents, Equity and Inclusion. University of Toronto has a position titled Vice-President, Human Resources and Equity. At Queen's University, the role of the Deputy Provost (Academic Operations and Inclusion) was revised in 2017 to focus on equity, diversity, and inclusion in all aspects of the university's operations. Laval University has recently appointed a "directrice du nouvel Institut Femmes, Société, Égalité, Équité" [director of the new institute for women, society, equality and equity]. While many of these senior positions are still held by people of privileged race (white Canadians), there are currently new noteworthy developments happening. One of these is the use of preferential hiring or targeted hiring language (e.g. McGill, Queen's, Ottawa, Alberta, Calgary) for both staff 
and faculty as a mechanism to enhance diversity through employment. Positions related to Indigenous engagement (senior administrators as well as faculty members) are often restricted to people who self-identify as Indigenous. Dalhousie University created a precedent in 2018 when it restricted its search for a new senior position (Vice Provost student affairs) to racially visible and Indigenous candidates (CBC News, 2018). More information about the senior leadership hiring practices can be found in institutional Employment Equity Policies, which was beyond the scope of this study. Many statements about "recruiting for faculty diversity" were made across the documents. University of Toronto reported the hiring in 2015-16 and 2016-17 of thirty new Black and Indigenous faculty members, who remain the least-represented groups within the Canadian academy (University of Toronto, 2018). The Université du Québec à Montréal adopted employment equality policies for women back in 1988 , before any government requirement, and has expanded it to include visible minorities, Aboriginal people, and people with disabilities (Montreal University, 2018). These are some steps incorporated in the hiring process that have contributed towards creating a more diverse hiring culture among $\mathrm{Ca}$ nadian universities.

Another common approach is to create distinct councils or committees within the organizational structure. For example, Queen's University has established a Council on Anti-Racism and Equity that helps promote engagement in initiatives to address racism and promote equity, diversity, and inclusion. Western University has put together committees for employment equity, women on campus, and barrier-free access, among others (Western University, web). Several universities (e.g. Waterloo, UBC) have created committees to create an Indigenization Strategy. While those offices and committees operate with secured capacity and resources, there is a possibility that they may remain designated equity pockets on campus, yet the broader strategic initiatives expressed in the documents suggest a move towards gradual campus-wide systemic change.

Policy documents are also referring to mandatory campus-wide training programs for researchers, senior administration members such as new deans, vice-deans, and academic unit heads, and tenure and promotion committees to address unconscious biases in decision-making (e.g. at the University of Waterloo, Queen's, and Western). Learning how to detect individual biases among decision-makers helps to bring a critical lens to who gets hired, showing institutional political commitment to enhancing opportunities for equity-seeking groups.

\section{Strategies Related to Student Recruit- ment}

Tracking student numbers (composition of student body) and focusing on student recruitment activities, sometimes with performance indicators attached, was a prominent theme in institutional attempts to enhance campus diversity. Most universities have developed plans for targeted recruitment campaigns. Institutional documents frequently stated the goal of attracting "top students from across diverse communities" (University of Alberta, 2016, p. 8). The two most often mentioned target groups were international students and Indigenous students. Eight universities out of 15 have developed separate Internationalization Strategies in order to focus their activities on international student recruitment, including the use of performance indicators to measure progress. For example, the University of Alberta's Internationalization Strategy stated, "By 2016 , we aim to count $10 \%$ of our undergraduate population and $25 \%$ of our graduate population as international students" (p. 2). Recruitment of Indigenous students has been addressed in a less campaign-like manner. Four institutions (University of Alberta, Manitoba, McGill, and Queen's) have stated specific performance indicators related to Indigenous student recruitment.

Institutional strategies to support student recruitment have varied from creating undergraduate student recruitment plans (University of Alberta, Dalhousie, Manitoba, Ottawa, Queen's, Toronto, UBC, and Western University), new admissions websites where (racialized) international student profiles are featured (University of Alberta), recruitment training for staff, and developing multiple pathway programs for entry. UBC has developed Aboriginal Access Studies to provide support for Indigenous students in their efforts to access higher education. University of Manitoba offers a free Access program for Indigenous peoples, residents of Northern Manitoba, low-income earners, and newcomers that prepares and transitions learners into degree programs at universities. Some faculties have adopted diversity admission policies. For example, the University of Ottawa's Faculty of Law has created admission categories to diversify the incoming classes of students with regard to their age, their In- 
digenous and immigrant status, and their socio-economic circumstances. The University of Manitoba's Faculty of Education has developed a diversity admission policy for their teacher education program following five diversity categories with enrollment targets. These steps taken by the faculties demonstrate proactive action that goes beyond institutional slogans to "embrace diversity" by making space for diversity. However, not all universities are there yet. Several universities in this study were still at the stage of conducting unit and institution-wide assessments to identify issues with student admission and retainment before moving forward.

As noted by scholars, student recruitment indicators are problematic as they may lead to treating students as market objects (see Stein \& de Andreotti, 2016), particularly if the individual student's unique needs behind those numbers are overlooked. Only by recognizing privilege, creating space, and making distinct programmatic supports available for equity-seeking student groups can institutions truly address the issue of equity, diversity and inclusion. The following section analyzes the new supports provided to students once they are enrolled in a university.

\section{Strategies Related to Programmatic Supports}

Along with the student recruitment activities, the policy documents address the availability of student support services in regard to scholarships, bursaries, student advising services, curriculum adaptations and new course offerings. One of the key barriers to university education in Canada is tuition fees for accessing higher education. Financial support is one of the most common strategies that institutions have adopted, providing scholarships and bursaries to students in need. For example, McGill University planned to increase its already existing student aid program from $25 \%$ to $30 \%$ of total net tuition revenues (McGill, 2017, p. 3). In 2017, UBC launched a fundraising campaign aiming to raise $\$ 100$ million in student support over three years for historically excluded student populations. Queen's University has received a \$2.2 million donation, which has enabled the creation of new bursaries for first-year Black Canadian students, first-year visible minority and racialized students, and first-year first generation students.

In addition, there are important programmatic supports provided for students. Institutions have been hiring permanent staff more frequently to support students' learning needs. Dalhousie University has hired a permanent advisor for its Indigenous Student Center to help with learning needs and advocacy tasks. It has also established a Black Student Advising Center that helps with employment, scholarships, and bursaries (Dalhousie University, 2018). Queen's University has appointed an inaugural Diversity and Inclusivity Coordinator within the Division of Student Affairs to increase the visibility of existing supports that are available for underrepresented students (Queen's University, 2018). At UBC, a Human Rights Advisor position was created in 2017 to offer a space for students' confidential conversations on campus (UBC, 2018). For faculty members, mentorship programs-especially among the CRC position holders-have become a standard activity.

Some institutions have addressed the needs of graduating students to make sure there is a smooth path to overcoming difficulties in finding a job, especially for students representing equity-seeking groups. At Dalhousie, employers were surveyed to explore opportunities to target historically underrepresented students for employment. Montreal University has made it one of their strategic goals to assist students, especially those with special needs, in their integration and successful completion of their studies.

There were many examples in this study of universities' broader institution-wide efforts to create awareness and change through curriculum. UBC has focused on working in partnership with the Indigenous community in efforts to develop culturally inclusive and safe curricula across the university. It has offered a number of training opportunities to help its staff in creating more inclusive classrooms. Workshops have included topics such as inclusive language, mispronunciation of names and misgendering, and inclusion beyond policy. University of Calgary listed over 100 courses and 30 degree options in areas that explore topics related to power, social justice, equity, multiculturalism, and diversity (University of Calgary, 2016). These activities have aimed to avoid the pitfall of equity and inclusion activities falling into small designated pockets within the organizational structure as opposed to creating broader systemic change. 


\section{Strategies Related to Research and Scholarship}

This theme emerged in relation to the availability of supports for equity-seeking faculty to support their activity through research grants, prioritizing EDI-related research areas and/or establishing new knowledge centers. The literature has suggested that increasing emphasis on research performance and limited ideas around what counts as legitimate knowledge is serving as a barrier to professional success for equity-seeking faculty members in Canada (Acker, Webber, \& Smyth, 2012). This analysis suggested that there were a few universities that recognized those barriers, setting aside financial resources for supporting the work of diverse researcher groups. For example, Dalhousie University introduced the Belong Research Fellowship for pre-tenured faculty members from equity-seeking groups with awards up to $\$ 10,000$ for research projects. The University of Alberta received an additional \$1 million gift from the Métis Scholar Awards Endowment Fund to recognize research work done by Indigenous faculty (University of Alberta, web). The eligibility criteria for the Queen's National Scholar (QNS) program were revised so that successful candidates must demonstrate their understanding and support of the principles of equity, diversity, and inclusion.

Several universities have concentrated their strategic efforts on strengthening their positions in research areas that focus on topics related to equity, diversity and inclusion. For example, the University of Manitoba has prioritized Indigenous research and scholarship. It has developed the University Indigenous Research Grant Program that aims to foster the inclusion of Indigenous perspectives and support non-Western ways of knowing in research (University of Manitoba, web). The University of Alberta has designated Research at the Intersections of Gender (RIG) as one of their signature areas of research and teaching, focusing on the importance of gender in its intersections with race, class, ethnicity, and religion. UBC has established Centers for Excellence in Indigenous Health (2014) and the Indian Residential School History and Dialogue Centre (2018), among other initiatives.

The analysis indicated that the majority of institutional efforts regarding research and scholarship amounted to tracking the gender and identity of CRC holders. While some efforts have been made in terms of creating new research grants and scholarships and supporting multi-disciplinary knowledge centers on topics around equity and inclusion, much more can be done to justify institutional commitment to research and scholarship on diversity-focused areas.

\section{Strategies Related to Institutional Cli- mate}

As policy documents should be treated not only as written texts but as processes, we looked for evidence on activities and initiatives that may have an influence on broader institutional climate creating certain attitudes, enforcing potential stereotypes, influencing perceptions on behaviors and relationships among and between groups. Hurtado et al.'s (1998) framework of campus life was applied. Statements about historical harm done to Indigenous peoples in Canada were the most common institutional strategy to express concerns over historical legacies across the policy documents. Eleven out of fifteen universities specifically made references to the Truth and Reconciliation committee's Call to Action in education, recognizing the impacts of colonialism in Canada. Most plans listed a wide range of activities initiated as part of the efforts of reconciliation. Historical disadvantage in relation to other equity-seeking groups was not mentioned in institutional strategic documents.

Psychological and behavioral climate on campus is hard to evaluate through policy analysis, as the language used in the texts is typically vague, allowing for wide interpretations and not always reflecting the perceptions or experiences of the targeted groups. We were able to collect information about activities that aimed to support inclusion-related values and behaviors in the documents. Most universities have organized diversity events, celebration weeks, lectures, training sessions, and workshops. For example, the University of Alberta has hosted an annual Equity, Diversity and Inclusion week since 2014 (University of Alberta, 2018). The University of Calgary has held events such as Diversity Week and Black History Month with talks and lecture serie (University of Calgary, 2017). The University of Toronto Scarborough campus has organized a "Rainbow Tie Gala" to celebrate their LGBTQIA2S+ community (University of Toronto Scarborough, web). A few universities (Alberta, McMaster) have developed smudging protocols and Ceremonial Guidelines to support spiritual and ceremonial practices that embrace Indigenous cultural traditions on campus (University of Alberta, web; McMaster University web). 
To address the issue of physical access for students with physical disabilities, McGill University significantly increased its budget in 2018-2019 for the Universal Access Capital Projects Working Group to finance capital projects that enhance physical accessibility to campus buildings and properties (McGill University, 2018).

Another common institutional strategy to demonstrate institutional supportive climate and appreciation of work has been the establishment of new award categories (e.g. Dalhousie University, McGill University, the University of Waterloo). While there has been a tendency to award mainly faculty and staff, the Division of Student Affairs at Queen's University has established a new Equity, Diversity, and Inclusion Impact Award for students who have demonstrated their commitment to furthering an understanding of different identities on campus Queen's University, 2018). Such awards create institution-wide awareness and media attention around the issues of diversity and inclusion and help to draw wider public attention to the specific barriers institutions aim to overcome.

\section{Conclusion and Discussion}

The goal of this paper was to understand how $15 \mathrm{Ca}-$ nadian research-intensive universities define equity, diversity and inclusion in their policy documents and then analyze the equity, diversity and inclusion strategies emerging from those documents through critical policy analysis. The following key findings emerged from the study. First, there was some variety in terms of how equity was defined and addressed in the policy documents. The majority of universities define equity as inclusion, focusing on removing institutional barriers to equal access to education. Fewer universities have taken a more radical approach, viewing equity as fairness that requires redistribution of resources. The most profound examples of this approach include the creation of diversity admissions policies for equity-seeking student groups, preferential hiring approaches for administration and faculty, and funding designated to equity-seeking groups for both students and faculty. It remains to be seen how successful Canadian universities are, especially in terms of the redistribution of resources, as institutional decisions are still predominantly made by the dominant racial group. Our analysis also indicated that universities that have established Diversity and/or Equity Offices were more likely to collect more detailed information, monitor EDI activities, and make proactive recommendations to senior leadership on potential improvements compared to those universities without designated offices. There also seemed to be a variance in terms of the assignment of responsibility for equity, diversity and inclusion. In some cases, it was on all faculty and staff and in other cases, the documents seemed to suggest that equity work belongs only within particular spaces (designated offices).

Second, our findings suggest that there are five main categories of institutional strategies related to engagement with EDI agendas: 1) political commitment; 2) student recruitment; 3) programmatic supports; 4) research and scholarship, and 5) institutional climate. As part of the political commitment, the analysis indicated strong involvement from the university administration to enhance equity agendas on campus. This was evident through prioritizing and funding of a wide range of activities that help to enhance equity agendas: establishing equity offices, creating new senior administration positions and implementing mandatory training for staff; engaging in targeted student and faculty recruitment with programmatic and research support available; implementing diversity admission policies, establishing scholarships and access programs for students; requesting curriculum changes. There seems to be a momentum happening across the universities, which is possible with political decisions made at the top leadership level. While, there still seems to be a continuous pattern of employing people of privileged race and gender in the majority of senior leadership positions, changes are occurring with more attempts to hire racialized (including Indigenous) people in these positions.

The institutional documents showed that universities are currently predominantly utilizing recruitment campaigns as mechanisms for achieving greater diversity on campus. The demographic changes in Canada show an increase in the number of Indigenous youth (Statistics Canada, 2016), which has focused institutional recruitment efforts on Indigenous students. In addition, focus on recruiting international students has been a longterm target for many U15 universities. There are clear economic benefits to universities associated with those recruitment strategies, which makes the availability of programmatic supports of utmost importance.

Our analysis shows that while there are programmatic supports available, more can be done in order to achieve a balance between increasing student recruitment and supporting the success of equity-seeking stu- 
dents while enrolled. For example, international students were not considered an equity-seeking group in the institutional policy documents. In institutional efforts to embrace equity, Canadian universities continue to collect significantly higher tuition fees from international students to ameliorate cuts in government funding (Guo, Y. \& Guo, S., 2017). There was limited evidence on articulating supports to international students in regard to cultural adjustment (food and climate), clarifying Canadian academic culture (e.g. plagiarism, expectations of students, relationship with faculty) or addressing social problems (e.g. arrival confusion, the maintenance of self-esteem, homesickness, making friends). Without those unique and often individualized supports, international students, as noted in the literature, can be minimized down to serving as "cash", "competition" or "charity" (Stein \& Andreotti, 2016) for the university, not fully integrated into many aspects of campus life.

On the research and scholarship front, the struggle for achieving equity and inclusion has been especially pertinent. There were very few universities that have listed targeted activities for addressing the unique research-specific needs of equity-seeking faculty. As a result of the Canadian federal governments' CRC programmatic requirements, all Canadian research-intensive universities are required to develop policies and are tracking institutional performance regarding equity, diversity and inclusion in hiring Canada Research Chairs. It is important to reiterate that this road towards stronger political attention to EDI issues in the CRC program has not been smooth sailing in Canada but rather a continuous struggle where change has been achieved only after engaging in a serious legal battle. Equity targets for the CRC program were established only after eight women filed a complaint with the Canadian Human Rights Commission in 2003, followed by a mediated settlement in 2006 (see Side \& Robins, 2007). Consequently, questions emerge regarding the motives of the institutional engagement with the EDI hiring agendas, wondering if this is an altruistic development from the part of the university administrations or a calculated survival strategy in the climate of fiscal restraints. Establishing various indicators may be a sign of a neoliberal measurement culture, yet those performance reports seem to hold institutions accountable to demonstrating their actual achievements in supporting equity, diversity and inclusion to the government and public.

To build a supportive institutional culture, a wide range of activities, including celebratory events and award categories have been put in place to recognize the value of diversity and create a more inclusive organizational culture in the long run. Overall, the data indicates that there is definitely momentum building towards supporting EDI agendas across Canadian universities. As such, this topic requires more in-depth analysis to get more insights from the implementation side of things. Our findings are derived from the policy analysis and need to be supported by the lived experiences of key stakeholder groups-such as university administration, equity-seeking faculty and student groups-to get a better understanding of how those policies have been designed, implemented, received, and experienced. Additional insights from university unions and student and faculty associations would provide valuable information on the topic. Furthermore, lived experiences of people would allow for examining of intangible factors such as the institutional culture, power relationships, behaviour, and overall campus climate, all of which are difficult to detect through document analysis. It would also allow for providing of additional perspectives on the overall motivations and rationales for universities engaging in the EDI agendas.

Nevertheless, the fact that policy documents show an increased tendency towards creating awareness and defining EDI issues from a critical perspective demonstrates that people in power are gradually starting to pay more attention to the voices of equity-seeking groups. Identifying institution-specific systematic barriers and addressing those with action plans and indicators incorporated in implementation reports gives hope for a broader and better-informed change. Policy documents influence action and activities listed in the policy documents are important steps towards initiating institutional change, while recognizing the need to include more voices from those on the receiving end of EDI policies.

There is no shortage in the academic literature of criticism regarding the tokenistic slogans universities have used to enhance equity, diversity and inclusion strategies (Clark et al., 2014; Henry et al., 2016; Iverson, 2007), and rightfully so. Achieving equity and inclusion is a complex and continuous task for higher education institutions. While many barriers still remain-and new ones are emerging-the analysis in this study showed that Canadian universities are gradually taking a pro-active approach to creating broader awareness and alleviating issues related to equity, diversity, and inclusion. The analysis presented in this paper aims to recognize that 
work and contribute knowledge that might be helpful for other institutions in similar and continuous efforts to build inclusive learning environments for all.

\section{Acknowledgements}

This work was funded by the Faculty of Education, University of Manitoba Start-up Grant and the University of Manitoba Undergraduate Research Award.

\section{References}

Acker, S., Webber, M., \& Smyth, E. (2012). Tenure troubles and equity matters in Canadian academe. British Journal of Sociology of Education, 33(5), 743-761.

al Shaibah, A. (2014). Educational equity in Canadian academe: Implications of neoliberal discourse and ideology (unpublished doctoral dissertation). Queen's University, Kingston, Ontario, Canada. Retrieved from https://qspace.library.queensu. ca/bitstream/handle/1974/12452/al\%20Shaibah_ Arig 201409 PhD.pdf?sequence=1

Bailey, K. A. (2016). Racism within the Canadian university: Indigenous students' experiences. Ethnic and Racial Studies, 39(7), 1261-1279.

Ball, S. (1990). Politics and policy-making in education. London, England: Routledge.

Ball, S. J. (1993). What is policy? Texts, trajectories and toolboxes, Discourse, 13 (2), 10-17.

Bowe, R., Ball, S. J., \& Gold, A. (1992). Reforming education and changing schools: Case studies in policy sociology. London, England: Routledge.

Brennan, J., \& Naidoo, R. (2008). Higher education and the achievement (and/or prevention) of equity and social justice. Higher Education, 56(3), 287-302.

Burnard P. (1991) A method of analysing interview transcripts in qualitative research. Nurse Education Today 11, 461-466.

CBC News. (2018, February 12). Dalhousie only seeking racially visible, Indigenous candidates for senior job. Retrieved from https://www.cbc. ca/news/canada/nova-scotia/dalhousie-universi- ty-recruitment-management-racially-visible-indigenous- 1.4531723

Chan, A. S. (2005). Policy discourses and changing practice: Diversity and the university-college. Higher Education, 50(1), 129-157.

Chun, E., \& Evans, A. (2018). Leading a diversity culture shift in higher education: Comprehensive organizational learning strategies. Abingdon-on-Thames, England: Routledge.

Clark, D. A., Kleiman, S., Spanierman, L. B., Isaac, P., \& Poolokasingham, G. (2014). "Do you live in a teepee?" Aboriginal students' experiences with racial microaggressions in Canada. Journal of Diversity in Higher Education, 7(2), 112.

Clarke, M. (2014). The sublime objects of education policy: quality, equity and ideology. Discourse: Studies in the Cultural Politics of Education, 35(4), 584-598.

Creswell, J. W. (1998). Qualitative inquiry and research design: Choosing among five traditions. Thousand Oaks, CA: SAGE Publications.

Dalhousie University. (2018). Diversity and Inclusiveness Strategy Progress Report. Retrieved from https://cdn.dal.ca/content/dam/dalhousie/pdf/cultureofrespect/Diversity-\&-Inclusiveness-Report-February-2018.pdf

Diem, S. \& Young, M. D. (2015). Considering critical turns in research on educational leadership and policy. International Journal of Educational Management, 29(7), 838-850.

Elo, S., \& Kyngäs, H. (2008). The qualitative content analysis process. Journal of Advanced Nursing, 62(1), 107-115.

Gaudry, A., \& Lorenz, D. (2018). Indigenization as inclusion, reconciliation, and decolonization: Navigating the different visions for indigenizing the Canadian Academy. AlterNative: An International Journal of Indigenous Peoples, 14(3), 218-227.

Gertler, M. (2016). A strategic moment for Canada. The Globe and Mail (July 21, 2016). Retrieved from http://www.theglobeandmail.com/opinion/a-strategic-moment-for-canada/article31019860/?page=all.

Government of Canada. (2014). Canada's international 
education strategy: Harnessing our knowledge advantage to drive innovation and prosperity. Retrieved from http://international.gc.ca/ global-markets-marches-mondiaux/assets/pdfs/overview-apercu-eng.pdf.

Government of Canada. (2017). Equity, Diversity and Inclusion Action Plan. Retrieved from http://www. chairs-chaires.gc.ca/program-programme/equity-equite/action_plan-plan_action-eng.aspx.

Government of Canada. (2018). Open letter from the Canada Research Chairs Program management to institutional presidents. Retrieved from http:ll www.chairs-chaires.gc.ca/whats new-quoi de neuf/2018/letter to presidents-lettre aux presidents-eng.aspx.

Government of Canada, (2019). Canada Research Chairs. About us. Retrieved from http://www.chairschaires.gc.ca/about us-a notre sujet/index-eng. aspx.

Guo, S., \& Chase, M. (2011). Internationalisation of higher education: Integrating international students into Canadian academic environment. Teaching in Higher Education, 16(3), 305-318.

Guo, Y., \& Guo, S. (2017). Internationalization of Canadian higher education: Discrepancies between policies and international student experiences. Studies in Higher Education, 42(5), 851-868.

Harper, S. R., \& Hurtado, S. (2007). Nine themes in campus racial climates and implications for institutional transformation. New Directions for Student Services, 2007(120), 7-24.

Henry, F., Dua, E., Kobayashi, A., James, C., Li, P., Ramos, H., \& Smith, M. S. (2016). Race, racialization and Indigeneity in Canadian universities. Race Ethnicity and Education, 20(3), 300-314.

Henry, M., Lingard, B., Rizvi, F., \& Taylor, S. (2013). Educational policy and the politics of change. New York, NY: Routledge.

Hoffman, G. D., \& Mitchell, T. D. (2016). Making diversity "everyone's business": A discourse analysis of institutional responses to student activism for equity and inclusion. Journal of Diversity in Higher Education, 9(3), 277.
Hurtado, S., Clayton-Pedersen, A. R., Allen, W. R., \& Milem, J. F. (1998). Enhancing campus climates for racial/ethnic diversity: Educational policy and practice. The Review of Higher Education, 21(3), 279-302.

Hurtado, S., Alvarez, C.L., Guillermo-Wann, C., Cuellar, M., \& Arellano, L. (2012). A modelfor diverse learning environments: The scholarship on creating and assessing conditions for student success. In J. C. Smart, \& M.B. Paulsen (Eds.), Higher education: Handbook of theory and research (vol. 26, pp. 41-122). Netherlands: Springer Science + Business Media B.V.

Iverson, S. V. (2007). Camouflaging power and privilege: A critical race analysis of university diversity policies. Educational Administration Quarterly, 43(5), 586-611

Jalovcic, D. (2017). Experiences of interaction for students with disabilities in online university programs. Retrieved from https://dt.athabascau.ca/jspui/handle/10791/239.

Kipang, S., \& Zuberi, D. (2018). Beyond Face Value: A Policy Analysis of Employment Equity Programs and Reporting in Ontario Public Colleges. Canadian Journal of Higher Education, 48(2), 169-185.

McGill University. (2017). Strategic Academic Plan. Retrieved from https://www.mcgill.ca/provost/files/ provost/20170509 final provosts strategic academic plan 2017-2022.pdf.

McGill University. (2018). Canada Research Chairs: Equity, Diversity \& Inclusion Action Plan. Retrieved from https://www.mcgill.ca/provost/files/provost/ equity diversity and inclusion action plan for the crc program.pdf

McMaster University (web). Smudging Protocol for the Burning of Traditional and Sacred Medicine. Retrieved from https://equity.mcmaster.ca/documents/ eio-smudging-protocol-2019.pdf

Michalski, J. H., Cunningham, T., \& Henry, J. (2017). The diversity challenge for higher education in Canada: The prospects and challenges of increased access and student success. Humboldt Journal of Social Relations, 1(39), 66-89. 
Montreal University. (2018). Plan d'action en matière d'équité, de diversité et d'inclusion pour le programme des chaires de recherche du Canada. [Action Plan for Equity, Diversity and Inclusion for the Canada Research Chairs Program]. Retrieved from https://recherche.uqam.ca/upload/files/uqamcrc-plan-action.pdf

Organisation for Economic Co-operation and Development (OECD). (2013). Education indicators in focus. Retrieved from https://www.oecd. org/education/skills-beyond-school/EDIF\%20 2013-N\%C2\%B010\%20(eng)-v9\%20FINAL \%20 bis.pdf.

Osborne, R. (2012). Diversity, equity and the universities: The role of the Federal Contractor's Program in Canada. British Journal of Canadian Studies, 25(2), 253-266.

Ostrowski, C. P. (2016). Improving access to accommodations: Reducing political and institutional barriers for Canadian postsecondary students with visual impairments. Journal of Visual Impairment $\&$ Blindness, 110(1), 15-25.

Ozga, J. (2000). Policy research in educational settings: Contested terrain. Buckingham: Open University Press.

Ozga, J. (2005). Modernizing the education workforce: a perspective from Scotland. Educational Review, 57(2), 207-219.

Pidgeon, M., Archibald, J. A., \& Hawkey, C. (2014). Relationships matter: Supporting Aboriginal graduate students in British Columbia, Canada. Canadian Journal of Higher Education, 44(1), 1-21.

Pidgeon, M. (2016). More than a checklist: Meaningful Indigenous inclusion in higher education. Social Inclusion, 4(1), 77-91.

Preston, J. (2008). The urgency of postsecondary education for Aboriginal peoples. Canadian Journal of Educational Administration and Policy, 86, 1-22.

Queen's University. (2018). Principal's Implementation Committee on Racism, Diversity, and Inclusion Implementation Report. (PICRDI) (2018). Retrieved from https://www.queensu.ca/principal/sites/webpublish.queensu.ca.opvcwww/files/files/QU-PI-

\section{CRDI-implementation-report-2018-04.pdf}

Riley, T., Mentis, M., \& Kearney, A. (2016). Equity and diversity. New Zealand Journal of Educational Studies, 51(2), 139-142.

Scott, C., Safdar, S., Trilokekar, R., \& El Masri, A. (2015). International students as 'Ideal Immigrants' in Canada: A disconnect between policy makers' assumptions and the lived experiences of international students. Comparative and International Education/ Éducation comparée et internationale, 43(3), 5.

Side, K., \& Robbins, W. (2007). Institutionalizing inequalities in Canadian universities: The Canada research chairs program. NWSA Journal, 19(3), 163-181.

Statistics Canada. (2016). Census of Population (Statistics Canada catalogue no. 97-560-XCB2006036). Retrieved from https://www12.statcan.gc.ca/census-recensement/2016/dp-pd/index-eng.cfm.

St. Denis, V. (2011). Silencing Aboriginal curricular content and perspectives through multiculturalism: "There are other children here". Review of Education, Pedagogy, and Cultural Studies, 33(4), 306-317.

Stein, S., \& de Andreotti, V. O. (2016). Cash, competition, or charity: International students and the global imaginary. Higher Education, 72(2), 225-239.

Stein, S. (2017). National exceptionalism in the 'EduCanada' brand: Unpacking the ethics of internationalization marketing in Canada. Discourse: Studies in the Cultural Politics of Education, 1-17.

Taylor, S. (1997). Critical policy analysis: Exploring contexts, texts and consequences. Discourse: Studies in the Cultural Politics of Education, 18(1) 23-34.

Trilokekar, R. D. (2010). International education as soft power? The contributions and challenges of Canadian foreign policy to the internationalization of higher education. Higher Education, 59(2), 131-147.

Truth and Reconciliation Commission. (2015). Truth and Reconciliation Commission of Canada: Calls to Action. Retrieved from https://nctr.ca/assets/reports/ Calls to Action English2.pdf.

UNESCO. (2015). Education 2030. Incheon Declaration. 
Framework for Action. Retrieved from https://unesdoc.unesco.org/ark:/48223/pf0000245656.

Universities Canada. (2017). Universities Canada principles on equity, diversity and inclusion. Retrieved from https://www.univcan.ca/media-room/media-releases/universities-canada-principles-equity-diversity-inclusion/.

University of Alberta. (2016). For the Public Good. Retrieved from https://www.ualberta.ca/strategic-plan/ reporting/build.

University of Alberta. (2018). CRC Equity, Diversity and Inclusion Action Plan. Retrieved from https://www. ualberta.ca/research/services/funding-opportunities/ canada-research-chairs/ualberta-action-plan

University of Alberta. (web). Smudging Guidelines. Retrieved from https://cloudfront.ualberta.ca/-l media/ualberta/vice-president-facilities-and-operations/documents/ceremonial-smudging/ceremonial-smudging-guidelines-v-8.pdf

University of British Columbia. (2018). CRC Equity, Diversity and Inclusion Action Plan.Retrieved from https://academic.ubc.ca/sites/vpa.ubc.ca/files/documents/EDIAP\%20-\%2013\%20DEC $\% 202018 \% 20$ EE.pdf

University of Calgary. (2017). Office of Diversity, Equity and Protected Disclosure Annual Report (20162017). Retrieved from https://www.ucalgary.cal odepd/files/odepd/odepd-annual-report-november-6-2017.pdf

University of Manitoba. (web). University Indigenous Research Program (UIRP) General Guidelines. Retrieved from https:/umanitoba.ca/research/ors/ media/UIRP instructions and guidelines.pdf.

University of Toronto. (2018). Canada Research Chairs Equity, Diversity and Inclusion Action Plan. Retrieved from http://www.research.utoronto.cal wp-content/uploads/documents/2018/12/UofT CRC EDI ActionPlan 12.13.2018.pdf.

University of Toronto, Scarborough. (web). Past events. Retrieved from https://www.utsc.utoronto.ca/edio/ past-events

Western University. (n. d.). Equity and Human Rights
Services. Retrieved from https://www.uwo.ca/equityl diversity/initiatives/index.html.

\section{Contact Information}

Merli Tamtik

merli.tamtik@umanitoba.ca

\section{Notes}

1 The Canada Research Chairs (CRC) program was established in 2000 by the federal government to create 2,000 research professorship positionsCanada Research Chairs-in eligible degree-granting higher education institutions. Government invests approximately $\$ 265$ million per year to attract and retain a diverse cadre of world-class researchers in Canadian postsecondary institutions (Government of Canada, 2019). 